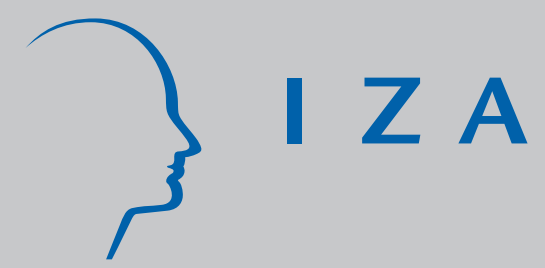

IZA DP No. 7450

The Unintended Consequences of Education Policies on South African Participation and Unemployment

Rulof Burger

Servaas van der Berg

Dieter von Fintel

June 2013

Forschungsinstitut zur Zukunft der Arbeit Institute for the Study of Labor 


\title{
The Unintended Consequences of Education Policies on South African Participation and Unemployment
}

\author{
Rulof Burger \\ University of Stellenbosch \\ Servaas van der Berg \\ University of Stellenbosch \\ and IZA \\ Dieter von Fintel \\ University of Stellenbosch
}

Discussion Paper No. 7450

June 2013

IZA

P.O. Box 7240

53072 Bonn

Germany

Phone: +49-228-3894-0

Fax: +49-228-3894-180

E-mail: iza@iza.org

\begin{abstract}
Any opinions expressed here are those of the author(s) and not those of IZA. Research published in this series may include views on policy, but the institute itself takes no institutional policy positions. The IZA research network is committed to the IZA Guiding Principles of Research Integrity.

The Institute for the Study of Labor (IZA) in Bonn is a local and virtual international research center and a place of communication between science, politics and business. IZA is an independent nonprofit organization supported by Deutsche Post Foundation. The center is associated with the University of Bonn and offers a stimulating research environment through its international network, workshops and conferences, data service, project support, research visits and doctoral program. IZA engages in (i) original and internationally competitive research in all fields of labor economics, (ii) development of policy concepts, and (iii) dissemination of research results and concepts to the interested public.
\end{abstract}

IZA Discussion Papers often represent preliminary work and are circulated to encourage discussion. Citation of such a paper should account for its provisional character. A revised version may be available directly from the author. 


\section{ABSTRACT \\ The Unintended Consequences of Education Policies on South African Participation and Unemployment ${ }^{*}$}

In the late 1990s the South African Department of Education implemented two policies that were meant to reduce the large number of over-age learners in the school system: schools were no longer allowed to accept students who were more than two years older than the correct grade-age and students could not be held back more than once in each of four schooling phases. Our analysis uses school administrative data and household survey data to show that these policies coincided with a decrease in school enrolment of at least 400,000 and possibly more than 900,000 learners. These policies appear to have pushed many students into the labour market at earlier ages than was observed for previous generations, which explains much of the sudden increase in labour force participation and unemployment during this period. However, since these individuals would probably have entered the labour market sooner if not for their poor employment prospects, we argue that the resulting increase in unemployment signifies a more accurate reflection of disguised unemployment that already existed in the mid-1990s rather than a deterioration of labour market conditions.

JEL Classification: J21, I25, J64

Keywords: South Africa, education, unemployment, participation

Corresponding author:

Servaas van der Berg

Department of Economics

University of Stellenbosch

Private Bag X1

Matieland, 7602

South Africa

E-mail: svdb@sun.ac.za

\footnotetext{
* The authors would like to thank Martin Gustafsson and John Knight for useful feedback on earlier drafts of this paper. All errors are our own. We also gratefully acknowledge the financial support of Economic Research Southern Africa in completing this study.
} 


\section{Introduction}

After South Africa's transition to democracy, the rapid rise in school enrolment that had already been a feature of the education landscape from the 1960 s continued unabated. This exacerbated pressure on educational and fiscal resources came at a time when the new government was confronted with a number of fiscal challenges. Such pressure made it more difficult to improve the resource situation in schools and particularly to reduce the extremely high pupil-teacher ratios in many schools that had formed part of the black school system (the Department of Education and Training or DET and the former homelands) in the apartheid era. The new unified Department of Education (DoE) became particularly concerned about the large numbers of over-aged learners in the school system. The argument was that many such over-aged learners were learning little, were unlikely to eventually pass matric, and were diverting resources from younger learners. Furthermore, this group's difficulty to pass matric would not leave them with better employment prospects once they left school.

Thus the DoE attempted to rectify this situation by implementing restrictions on who could be accepted into schools and how frequently students could be held back. Due to the sensitive nature of such policies and the lack of viable education alternatives for those forced out of schools (Further Education and Training (FET) colleges could not realistically accommodate these numbers), little is known about the exact nature of the policies, as will be discussed later in this paper.

The introduction of these educational policies coincided with some important changes in aggregate labour market outcomes. There occurred in the same period an inexplicably large and sudden increase in labour force participation, which increased the already high unemployment rate. Attempts thus far by researchers to explain this sudden spurt in labour market participation could account for, at most, a proportion of this increase. This paper puts forth an argument that a substantial part of the rise in participation and unemployment may be attributed to unintended consequences of more rapid grade promotion and restrictions on over-age learners in schools, which pushed many youths through the school system and into the labour market at a time when unemployment was already high. Therefore, while these policies were intended to contribute positively to the long term problems associated with education quality (and by implication the skills supplied by future labour market entrants), they did not take into account the immediate labour market impacts that would result without feasible alternative skills development opportunities for those that were affected.

The paper sets about arguing this proposition in the following way: Section 2 deals with trends in labour market outcomes over part of the post-apartheid era, but with the attention 
focused on the late 1990s and early 2000s; Section 3 discusses the educational policies of restrictions on over-age learners in schools and grade repetition; Section 4 contains an empirical investigation of the coincidence of this policy and trends in the labour market; Section 5 considers the unintended consequences of the restrictions on labour market outcomes; and Section 6 concludes.

\section{Trends in South African labour market outcomes in the post- apartheid era}

The long-term increase in the South African unemployment rate since the 1970s (Seeking and Nattrass 2006) is a subject that warrants separate investigation, but which we briefly review; a large proportion of this trend can be attributed to long-term shifts in the structure of labour demand (Bhorat and Hodge, 1999), so that the current labour market discourse revolves around a "skills shortage" and how appropriate skills can be strategically developed to reduce unemployment. Over this same period, the apartheid government followed a policy of segregated racial education systems, the effect of which is still manifest in vast differences in school quality and labour market outcomes for different groups in society.

However, the fact that unemployment continued to rise at an alarming pace from $31 \%$ in 1995 to $42 \%$ in 2003 (by the broad definition) suggests that the transition from apartheid

policies did not only fail to curtail the long-term trend, but that unemployment may have even been exacerbated by policies that were intended to subdue it. By all expectations, labour market prospects in the new South Africa should have improved: economic growth should supposedly have translated into greater opportunity for the previously marginalised, who could capitalise on the improved levels of education that younger generations had accumulated, in the context of new, anti-discriminatory labour market legislation. In the absence of these anticipated benefits, many commentators started referring to "jobless growth", though a number of subsequent studies of labour market trends over this period (Bhorat (2004), Banerjee et al. (2007)) have convincingly refuted this supposition. The question then remains why progressively greater stocks of human capital did not translate into lower unemployment rates in the post-apartheid period.

To understand this, labour market researchers have contrasted the relatively robust increase in labour market absorption with the even quicker rise in labour force participation as an intermediate explanation for continued increases in unemployment (Banerjee et al. (2007), Branson and Wittenberg (2007)). Together, this specific dynamic between the two sides of the labour market provides an explanation for rising unemployment in the post-apartheid period that has become commonly accepted in the academic literature. The causes for the rise in labour force participation, however, require more detailed analysis, and are the subject of the rest of this paper. According to data from Statistics South Africa's (StatsSA's) 
household surveys, as summarized in Table 1, employment grew at $2.8 \%$ per year between 1995 and $2007^{1}$, compared to the slower growth of $1.9 \%$ per year of the working age population. As a result, the share of the working age population that worked actually increased over the period, suggesting that labour demand had indeed expanded in response to economic growth. However, job creation could not keep up with the $4.6 \%$ per year growth in the labour force. Consequently, the unemployment rate increased.

[Insert table 1 here]

Figure 1 shows the broadly defined labour force participation rate and unemployment rate between 1995 and 2007. This illustrates that the rapid labour force growth was mainly due to a 13.8 percentage point increase in the participation rate between 1996 and 2002, after which point participation actually remained quite stable. As the figure shows, apart from this sudden spurt in the supply of labour, there were little other increases in participation or unemployment in the post-apartheid era. It is possible that the specific events of the period shortly after the transition, until about 2003 (when the sustained business cycle upswing finally started to assist in decreasing unemployment) could help us understand the currently high levels of labour force participation and unemployment.

\section{[Insert figure 1 here]}

A collection of different explanations has been put forward for the speedy increase in labour force participation. As mentioned above and illustrated below, these do not fully explain the large entry into the post-apartheid labour market. Foremost among these are demographic and household changes, which were associated with push factors into the labour market. Casale and Posel (2002) explored the changes in participation by gender and particularly characterised the 1995-1999 period as one of a "feminisation" of the labour force, driven by rapid labour market entry amongst previously inactive women, particularly amongst black Africans. They explored a number of hypotheses to explain this trend and ascribed it mainly to higher educational attainment, a decline in marriage rates among women and a decrease in the share of women who lived in households with employed men. As is shown below, explicitly controlling for these factors goes some way towards explaining differences in participation rates across generations, in particular for black females. However, these factors do not account for the sudden increase in labour market entry of the youngest generations of both genders, so that more recent events and policies (other than the long-run demographic changes that they explore) must be considered.

\footnotetext{
1 This figure probably overstates the number of jobs created. Numerous changes in questionnaire design occurred in the 1990s in an attempt to improve capturing of low-income jobs, so that the observed expansion of employment may include an artificial increase in informal sector employment.
} 
Ntuli (2007) decomposed the increase in participation amongst African women into differences in the levels of versus the returns to productive characteristics between 1995 and 2004. She found that the increased participation rate could be ascribed almost exclusively to a change in the behaviour of women rather than to changes in the levels of individual characteristics (as suggested by Casale \& Posel, 2002). In recent generations, women entered the labour market more readily than those with similar levels of education in previous generations, and they were more likely to participate at stages in their life cycle in which women previously chose to stay outside of the labour market. This conclusion is consistent with the finding by Mlatsheni \& Rospabe (2002) and Branson \& Wittenberg (2007) that the current youth cohort has borne the brunt of the unemployment increase, following their greater propensity to participate earlier in life. This study adds to this literature by understanding the role of the DoE's more recent schooling policies as a short-run push factor into the labour market, against longer term demographic trends that had altered participation patterns across generations.

Most of the above studies compared labour market outcomes between two years. However, such a comparative-static approach risks overlooking certain aspects of the inherently dynamic decisions that individuals face. Birth cohorts (individuals born in the same year) are likely to share similar characteristics that affect their labour market experiences throughout their lifetimes (such as a similar quality of education, similar economic opportunities affecting their decisions on whether to continue their education, and similar opportunities when they consider whether to enter the labour market). Further, members of the same cohort may have similar perceptions regarding gender roles and also regarding the trade-off between household and market production. Observing differences between individuals from different generations opens a way of understanding the effect of historical (represented by older generations) and recent (represented by recent entrants) dominant societal events and policies on current labour market decisions. If there is a strong cohort-specific component to these and other unobservable characteristics, then the labour market outcomes for a specific birth cohort may differ systematically from those of cohorts born earlier or later. Such effects may be incorrectly ascribed to age or time effects, unless one specifically controls for these cohort-specific differences. In section 6 this study explicitly controls for these factors in order to isolate generational impacts.

Burger and Woolard (2005) found that, although the overall unemployment rate has risen across all age groups between 1995 and 2002, the unemployment rate for any particular birth cohort remained remarkably stable over this period. This implies that no single generation experienced a markedly increased probability of unemployment over time. Rather, recent entrants had a much higher probability of being unemployed from the outset of their first job search, which persisted throughout their working lives. Increases in post-apartheid unemployment could therefore, almost exclusively, be linked to the experience of this group. 
Birth cohort panels are ideally suited to disentangle the effects of changes over time, over the life cycle or across birth cohorts. In the current context it is important to note that school policies affected some cohorts and not others, so that the identification of cohort effects becomes necessary in understanding policy impacts. Branson and Wittenberg (2007) used such birth-cohort panels to focus on the change in the unemployment rate for birth cohorts. They observed a large increase in the participation rates of black women between the 1998 OHS and the September 2000 LFS. They found that younger cohorts of black men and women entered the labour market sooner than their older counterparts, but that their age-employment profiles remained similar to those of older generations. The combined result was a higher unemployment rate for more recent labour market entrants, who were absorbed into the labour market only at ages typical for older generations. Their nonparametric analysis stopped short of analysing the potential causes for the acceleration in participation amongst the most recent generations.

Burger and Von Fintel (2009) decomposed the variation in participation, employment, unemployment and earnings along the dimensions of time, age and birth cohort using a methodology proposed by Deaton (1997). This allowed them to identify the components of the participation decision associated with changes in the business cycle (time), the individual's life cycle (age) and unobservable generation-specific (cohort) effects. They found a steady generational increase in participation among black and white women, but that this variation did not fit the sudden increase in participation observed for the youngest generation of black men and women, when they entered the labour market between 1997 and 2003. Hence, this paper will proceed to search for a reason for this well-documented and large scale entry into the labour market.

Finally, one should also consider the possibility that changes in the accuracy of capturing employment and labour force participation by Statistics South Africa in the late 1990s could have been responsible for at least part of what appears to have been upward trends observed in this period, an issue addressed by Yu (2008).

While many papers have referred to the role of the expanding access to education in the rise in labour supply, the literature has been relatively silent regarding the role of educational policy in explaining this large shift into the labour market. This paper now discusses two such policies that may have been important in driving this trend.

\section{Restrictions on over-aged learners and grade repetitions}

A high share of South African youths have historically chosen to stay in school for long beyond the normal school-going age due to late school entry, high repetition, drop-out and drop-in rates and the high unemployment rate amongst young workers with less than completed secondary education. In 1998 60\% of Grade 12 learners were older than the 
correct grade-age (Guluza \& Hoadley, 1998, p. 1). There are indications (discussed in section 4) that a large proportion of the over-age children remaining in school were black and lived in rural areas, perhaps the group that was also most likely to struggle to find employment otherwise. In contrast, early drop-out at about age 15 was most common amongst the coloured population, perhaps because of the pull of better labour market prospects that many of them faced compared to blacks (Hofmeyr 2011).

This presence of a large group of over-aged learners contributed to maintaining the already high class sizes in schools, which imposed a negative externality on pupils of the correct grade-age while tying up scarce resources in the education system. In an attempt to rectify this situation, the DoE phased in restrictions on over- and under-aged learners in the late 1990s, as well as limiting the number of times a student could be held back. Both of these policies would have decreased the number of over-aged learners in the school system. Since the age of first enrolment and age restrictions in the school system influence school leaving and often thereby also labour force participation rates, this policy may have contributed to the sudden increase in South African unemployment in the late 1990s. The correspondence between being an over-age individual and facing greater risks in finding employment has important implications for this group's transition into the labour force.

Shortly after political transition the DoE discussed - albeit in very vague terms - a strategy to reduce the large numbers of over-aged learners in schools (Republic of South Africa, 1995). This document refers to eliminating over-aged enrolment "in time" (1995, p. 36) with such a policy to be "enforced by the provincial Ministries of Education for the designated age group, on the basis of designated magisterial districts, until by stages the whole country is covered". This suggests a plan to phase in such a policy progressively by geographical regions. Given that South Africa's constitution guarantees all learners a basic level of education, the implementation of this policy was fraught with complications from the start. It was initially envisioned that the affected group of over-aged learners would be absorbed into alternative Further Education and Training colleges outside of the schooling system, where they would gain the appropriate skills required to successfully transition into the labour market (Republic of South Africa, 1995). However, Guluza \& Hoadley (1998) believe that by the time this policy was suggested, the "FET alternative" was already inaccessible to many potential FET candidates due to the scarcity of such institutions in rural areas and the often high fees. More conveniently located and cheaper schools therefore remained a more suitable educational alternative for most of these individuals. The implication for learners subjected to the policy is that they were likely to discontinue education and enter the labour market, due to a lack of viable alternatives.

Nevertheless, a shift in focus towards normalising the age profile was clearly a policy priority. In 1998 the Minister of Education published Age Requirements for Admission to an Ordinary Public School, which defined the appropriate age for admission to a certain grade as 
"the grade number plus 6" (Department of Education, 1998). However, the notice itself seemed to have been more concerned with the enrolment of under-age children in Grade 1, and - perhaps due to the sensitive nature of this policy - official DoE documents describing the implementation of restrictions on over-aged learner admissions are hard to come by. One is therefore left to infer much about the implementation details from school data, the policy documents of provincial education departments and other research papers. One document of the Department of Education hints at what the policy intended: "Provisions for conditions of admission of learners to public schools as well as age grade norms are further elaborated on in the Admissions Policy for Ordinary Public Schools (Department of Education, 1998) that came into effect in January 2000. By Grade 9, which marks the end of compulsory basic education, the learner should be 15 years old. Recognising that the problem of over-age learners will not be eliminated immediately, the policy states that the onus will be on schools to place learners who are above the normal age for a grade in a 'fasttrack facility' to help bring them in line with their peer group. Learners over the age of 16 wanting to attend school will be referred to adult education centres." (Department of Education: 2000, p.24). Although this policy was only formally promulgated in 2000 at national level, it appears to have been informally accepted as policy in some parts of the system before that.

It is not clear to what extent this policy was phased in across provinces in the way that was initially envisioned, but a study by Guluza \& Hoadley (1998) found that - at least with respect to restricting access to under-aged learners - schools were "caught in the middle between policies which require them to exclude [these] learners and pressures within the school and from the community which push them towards accepting these learners". It therefore seems unlikely that this policy had been uniformly enforced in all schools.

At about the same time, the Department of Education instituted new promotion and repetition policies. According to the OECD review of South African education, in 1998 "an admissions policy was issued that set norms for learners to proceed through school with their age cohort", "in order to improve the internal efficiency of the education system" (OECD 2009, p.51). These policies specified that any learner could only repeat once during any of the four education phases, i.e. the foundation phase (Grades 1 to 3, although Grade R has now been added to that), intermediate phase (Grades 4 to 6), the senior phase (Grade 7 to 9) or the further education and training phase (Grades 10 to 12) (OECD 2009). The policy is generally less strictly applied in Grades 1 and 2, where issues of under-age entry into schools and school readiness enter decisions on promotion and retention. The policy also in practice excludes Grade 12, as passing Grade 12 depends on success in the matriculation examination. On the other hand, it is not clear that the "weeding" that is observed in the system (holding back weak performing learners in Grade 11 to improve the matric pass rate) may imply some deviation from the formal promotion policies in the further education and training phase. 
DoE administrative data show that in the middle of a long-term trend of gradually growing enrolment numbers there occurred a sharp and sudden drop in enrolment between 1998 and 2002 (Kraak, 2008, p. 12), which Perry and Arends (2003: 304) ascribe to "the natural saturation of the system, and education department policy to limit under-age enrolment in Grade 1 and excessive repeating of all grades". Similarly, the number of matric candidates decreased by fully 20\% between 1998 and 2003 (Figure 2) - this trend could not be affected by the policy not to admit under-age learners into Grade 1, and could therefore highlight the exit of over-age learners. Provincial policy documents indicate that by 2003 the directives on over-age children had already been adopted, along with the promotion of the FET system (Western Cape Education Department, 2003). According to documents from that province, schools in the Western Cape were to deny admission to learners who were more than two years older than the appropriate grade-age; similar policies seemed to have applied in other provinces. Given that schooling is compulsory for all learners until the age of 15 , the affected individuals would be those who were i) older than 15, ii) more than two years older than the correct grade-age, and iii) wanted to enrol in school after 1998. Due to the higher repetition rates in historically black schools, this policy should by implication have affected black learners (both boys and girls) more directly than white learners.

A factor that may also have contributed to the implementation of the over-age policy, or to the choice of children to leave the school system, was the increased pressure applied by the education authorities on schools to improve their matric pass rates. Many schools responded to this by failing weaker learners in Grade 11 to reduce potentially high matric failures, despite the repetition policy that frowns on much repetition of grades in the school system. In addition, for similar reasons, schools became less accommodating towards children, particularly older ones, who had failed matric and wanted to repeat. One result may have been that many children may earlier have given up hope of achieving matric, thus also encouraging earlier entry into the labour market. The effect of the combination of over-age restrictions and weeding on matric data is evident from Figure 2, with the strong upward trend in the number of candidates due to improved progression through the school system more than cancelled by these phenomena in the late 1990s.

[Insert figure 2 here]

\section{Empirical investigation of schooling policies}

\subsection{The effect on total school enrolment}

In order to further investigate the effects of these policies, we now turn to two different data sources: the DoE administrative data and the Stats SA household surveys. Table 2 reports the school enrolment figures obtained from both sources. According to the DoE data the 
number of pupils in school (Grades 1 to 12) decreased by almost 425,000 between 1998 and 2003. We can estimate the same change using the household surveys, although this is complicated by the fact that prior to 1999 these surveys only asked whether individuals were attending "any educational institution" and hence did not allow any distinction between those in school and those in other educational institutions. However, comparing the estimated number of learners enrolled in school in the 1999 OHS and the September 2003 LFS shows an even stronger decrease in enrollment of almost 515,000.

There are various reasons why the two data sources would produce different estimates. It could be that changes in Stats SA's sampling methodology (as discussed in Yu (2008)) led to an artificially large decrease in the number of learners. Alternatively, the discrepancy may have been because the annual school survey that is the basis of departmental data for schools may have under-captured the number of over-aged learners due to administrative pressure to portray improved performance. However, the fact that a very similar trend can be identified across two very different datasets is evidence that what we observe is an actual decrease in enrolment, rather than some administrative error or a sampling anomaly. Also, the fall in enrolment in the household surveys amongst individuals that were 15 years and older (column 3) implies that this decrease could not have been caused solely (or even primarily) by restrictions on the first enrolment of under-aged children.

[Insert table 2 here]

It is possible to further investigate the role of age restrictions using the household surveys by defining the over-aged learners in our household data as those who i) were more than two years older than the correct grade-age, and ii) were enrolled in school. Using this definition, column 4 in Table 2 shows that the number of over-aged learners decreased by more than 865,000 between 1999 and 2003. The fact that this decline exceeds the total decrease in enrolment suggests that the underlying long-term trend of gradually increasing enrolment driven less by population growth than by greater access to schools and an increased demand for more secondary education - continued for normal-aged students even as the over-age restrictions were being implemented. Of course, if the enforcement of age restrictions was already implemented in 1998 (as is suggested by the policy documents and the administrative data), then the number of over-aged learners who left the school system may be even larger than the 865,000 estimated in Table 2 .

A brief examination of the characteristics of these over-aged learners shows that in 1999 they were particularly prevalent amongst rural-dwellers of the black population group. They were more likely to be male than female and more likely to reside in the Eastern Cape, Limpopo, Free State or Mpumalanga than in particularly the Western Cape or Gauteng. The probability of being an over-aged learner increased with age until the individual turned 21, and then steadily decreased. These results may reflect the quality of schooling received by different cohorts of South Africans, but also suggest that the decision to remain in school 
despite numerous grade repetitions was affected by one's labour market prospects. Individuals who realised that they had a poor chance of finding work without completed secondary education may have believed that there was little opportunity cost to remaining in school in the hope of eventual advancement. This situation was especially likely in the previously black part of the schooling system, where there appears to be a weaker link between student performance and grade promotion (Lam, Ardington and Leibbrandt, 2011).

Turning now to the effect of these policies on enrolment, Figure 3 plots the share of the population that was both in school and over-aged for different age groups in 1999, 2001 and 2003. In 1999 the share of each age cohort that was still in school and three or more years older than the normal grade age was above $20 \%$ for all ages between 16 and 23, and reached a peak of $28 \%$ for 21 year-olds. Although most over-aged pupils were in their late-teens and early twenties, a non-negligible share of 25-30 year-olds were still in the school system. By 2001 there had been a marked downward shift in the curve as some over-aged students were not allowed entry and other "would-be repeaters" were progressing through the school system more rapidly. During this period most of the decrease occurred for those aged 18 or older, which may reflect that these were the individuals most affected by the over-aged restrictions.

[Insert figure 3 here]

Between 2001 and 2003, there was only a very small additional downward shift at these older ages, whereas there occurred a large decrease in the share of over-aged learners aged 10 to 18. It is possible that forward-looking learners who have fallen behind in the early grades may be leaving school in anticipation of not being able to complete their secondary education in this era of age restrictions. Alternatively, more lenient promotion policies may have contributed to higher pass-rates at early grades, and this could also account for part of the drop in the number of young over-aged students.

\subsection{Identifying the separate effects of age restrictions and faster grade promotion on total school enrolment}

\subsubsection{A dynamic model of schooling progression}

Most of the preceding analysis investigated the effect of either of the two schooling policies on total school enrolment, without being able to distinguish between the two in the aggregate figures. This section will briefly attempt to separately identify the effects of age restrictions and faster grade promotion, by estimating the parameters of a dynamic school progression equation and then simulating the separate effects of the different policy scenarios. 
In order to arrive at an equation for schooling promotion and enrolment we note that at the beginning of any year $t$ there are three types of individuals with $s$ years of schooling: i) those who had $s-1$ years of completed schooling at the beginning of period $t-1$ and who successfully completed another grade during this year, ii) those who had $s$ years of schooling in period $t-1$ and did not enrol in school, and iii) those who had $s$ years of schooling in the previous year and did enroll but failed to be promoted. These dynamics are reflected in the equation for members of birth cohort $c$ as

$$
N_{c, s, t}=\left\{\left(1-\theta_{c, s, t-1}\right)+\left(1-\lambda_{c, s+1, t-1}\right) \theta_{c, s, t-1}\right\} N_{c, s, t-1}+\lambda_{c, s, t-1} \theta_{c, s-1, t-1} N_{c, s-1, t-1} \text { [1] }
$$

where $N_{c, s, t}$ is the number of individuals from birth cohort $c$ who have $s$ years of completed schooling in period $t, \theta_{c, s, t}$ is the share of cohort $c$ individuals with $s$ years of completed schooling who are enrolled in school in period $t$, and $\lambda_{c, s, t}$ is the grade $s$ promotion rate for members of cohort $c$ in period $t$. Of course, grade promotion cannot increase the number of individuals with no schooling or decrease the number with the maximum schooling years.

\subsubsection{Minimum distance estimates}

The Stats SA household surveys provide us with data on individuals' schooling levels, their birth year, enrolment decisions ${ }^{2}$ and sampling weights in different surveys, which allow us to estimate the aggregates $N_{c, s, t}$ and $\theta_{c, s, t}$ using simple sample averages. Furthermore, the promotion rate is a deterministic function of the values of $N_{c, s, t}$ and $\theta_{c, s, t}$ for lower levels of schooling:

$$
\lambda_{c, s+1, t-1}=\frac{\Delta N_{c, s, t}-\lambda_{c, s, t-1} \theta_{c, s-1, t-1} N_{c, s-1, t-1} 1(s>0)}{-\theta_{c, s, t-1} N_{c, s, t-1}} \text { if } s \leq S_{\max }
$$

and can in principle be iteratively estimated by replacing all of the population quantities by their sample counterparts. In practice sampling variation and measurement issues will distort the estimation of all of these parameters, and the promotion rates in particular ${ }^{3}$.

In an attempt to reduce the effect of sampling and measurement error, we use a minimum distance estimator to estimate the parameters of an internally consistent dynamic schooling progression model. We start by rewriting a cohort size-scaled version of equation [1] in error form:

\footnotetext{
${ }^{2}$ In order to estimate enrolment and progression rates for the period prior to 1999 we define school enrolment as being enrolled in any educational institution but having fewer than 12 years of completed schooling. Note that this definition differs from that used to estimate enrolment in Table 2, but produces a similarly sized decrease in enrolment between 1999 and 2003 of 497,297 (compared to 514,319 for the more accurate definition).

${ }^{3}$ Undersampling $N_{c, s, t-1}$ will not necessarily affect the estimation of $\theta_{c, s, t-1}$ but will simultaneously increase the numerator and decrease the denominator of $\lambda_{c, s+1, t-1}$. This issue is particularly problematic for uncommon combinations of $c, s$ and $t$, and can lead to estimates of $\lambda_{c, s+1, t-1}$ that lie outside of the unit interval.
} 


$$
\frac{\widehat{N}_{c, s, t}}{\widehat{N}_{c, t}}=\left\{\left(1-\hat{\theta}_{c, s, t-1}\right)+\left(1-\hat{\lambda}_{c, s+1, t-1}\right) \hat{\theta}_{c, s, t-1}\right\} \frac{\widehat{N}_{c, s, t-1}}{\widehat{N}_{c, t}}+\hat{\lambda}_{c, s, t-1} \hat{\theta}_{c, s-1, t-1} \frac{\widehat{N}_{c, s-1, t-1}}{\widehat{N}_{c, t}}+u_{c, s, t}[3]
$$

The cohort and grade-specific enrolment rates are assumed to be smooth functions of age $a$ (which is normalised to lie between 0 and 1 for ages from $s-6$ to 30), and restricted to lie within the unit interval:

$$
\theta_{c, s, t}=\Phi\left(\sum_{j=0}^{6} \beta_{j, s, t} \sqrt{2} \cos (\pi j a)+\beta_{J+1, s} c\right)
$$

where $\sqrt{2} \cos (\pi j a)$ is an orthonormal basis function often used in non-parametric series estimation $^{4}$ and $\Phi($.$) is the cumulative density function for a standard normal distribution. The$ smoothing parameter $J$ represents the number of bases that are used to fit the function ${ }^{5}$. The coefficients $\beta_{j, s, t}$ are restricted to be time invariant before 1998 and after 2003 while changing linearly between 1998 and 2003 - which will allow the data to reflect the gradual implementation of restrictions on over-aged learners - and are specific to the different schooling phases. Our specification also includes a linear generational trend, so that longterm changes in enrolment are not opportunistically attributed to the schooling policies that are the interest of this study. Similarly, the cohort and grade-specific promotion rates are specified as

$$
\lambda_{c, s, t}=\Phi\left(\sum_{j=0}^{1} \gamma_{j, s, t} \sqrt{2} \cos (\pi \cdot a)+\gamma_{J+1, s, t} c\right)
$$

where the $\gamma$ coefficients face the same restrictions as the $\beta$ coefficients. We choose fewer bases for the promotion rates specification, since these estimates were found to be more sensitive to the effects of sampling error.

Assuming that at age 5 each cohort only consisted of individuals with no education, equations [3], [4] and [5] are used to produce estimates of the enrolment and promotion rates, as well as the dynamics of cohort education shares $\frac{\widehat{N}_{c, s, t}}{\widehat{N}_{c, t}}$ for ages from 6 to 30 . Numerical optimisation techniques are then used to minimise the distance between these cohort education share and enrolment rate estimates and their corresponding sample moments.

Figure 4 compares the predicted age-specific enrolment and promotion rates for different schooling phases obtained from the pre-implementation (1995-1997) and postimplementation (2003-2005) minimum distance coefficient estimates. The graphs compare the hypothetical rates for a given cohort (those born in 1995), so that the observed differences are not affected by the gradual generational trend towards higher enrolment and faster promotion. We observe that promotion and enrolment rates are high and very high respectively at the correct grade ages (represented by vertical lines in Figure 4), but then decrease for older learners. Furthermore, the effect of both the overage restrictions and

\footnotetext{
4 This type of non-parametric estimator has the benefit of being much quicker to estimate than kernel estimators, since it need not be evaluated separately at each age. This is a crucial advantage when combining a non-parametric specification with numerical optimsation techniques.

${ }^{5}$ Larger values of $J$ represent more flexible specifications, and is therefore analogous to choosing narrower bandwidths in non-parametric kernel estimation.
} 
faster grade promotion are clearly evident from these estimates. The enrolment of normalaged students is very similar before and after the implementation of the policy, whereas a large decrease occurred for individuals who were a few years older than the correct grade age. Faster grade promotion appears to have been achieved by increasing the pass rate for learners who are at or slightly above the normal grade age, whereas the pass rates for those who were much older than the normal grade age actually decreased between 1997 and 2003.

\section{[Insert figure 4 here]}

\subsubsection{Policy simulation results}

The enrolment and promotion rate estimates can be used to simulate the effect of the overage restriction and faster grade promotion policies separately, in order to isolate the relative contribution of each through the different cohorts and periods. All policy scenarios below take the 1995 values of $N_{c, s, t}$ as given and then simulate the values of $\widehat{N}_{c, s, t}$ for subsequent years according to equation [3]. The simulated total enrolment rates for all 15-30 year olds are plotted in Figure 5.

The first scenario uses the each of the estimated values of $\hat{\lambda}_{c, s, t}$ and $\hat{\theta}_{c, s, t}$ over all years, and hence corresponds to the observed schooling outcomes in the presence of both the overaged restriction and the accelerated grade promotion policies. We can observe that total school enrolment decreased from 40\% of 15-30 year-olds in 1995 to about 32\% in 2003. The second case fixes the enrolment and promotion rates to their average values across the 1995-1997 period, and therefore represents the scenario in which neither policy was implemented and school enrolment and grade promotion continued to occur according to their pre-1998 rates. In this case total enrolment only decreases very gradually to $38.4 \%$ in 2003. The comparison of these two scenarios indicates that the policies had jointly reduced the number of learners by 923000 between 1997 and 2003. The third scenario is one in which the grade promotion rates were allowed to vary according to their estimated values, while the enrolment rates were fixed at their pre-1998 levels. This represents the hypothetical case in which only faster grade promotion was implemented without also introducing age restrictions. The predicted total enrolment share shows that this policy led to virtually no change in the enrolment share (relative to the no change scenario). The fourth scenario, in which the over-aged restrictions were implemented but the faster grade promotion policy was not (by fixing the grade promotion rates to pre-1998 levels), demonstrates that the sudden drop in learners that is observed in the aggregate data was almost entirely attributable to the stricter age restrictions.

[Insert figure 5 here] 
Given the results in Figure 4, which show that both enrolment and promotion rates changed substantially between 1997 and 2003, it may seem surprising that the accelerated grade promotion contributed so little to the decrease in school enrolment. However, whereas a decrease in the enrolment rate has a direct proportional effect on total enrolment, the effect of an increased promotion rate is more indirect. Figure 4 demonstrated that the probability of enrolment is a decreasing function of both age and schooling year. The typical individual is therefore less likely to be enrolled in school in period $t+1$ than in period $t$, regardless of whether she passes or fails the current grade. An increase in the grade promotion rate will only decrease total enrolment by the extent to which the decrease in enrolment associated with an additional year of schooling exceeds the decrease in enrolment associated with an additional year of age. This means that an increase in the grade promotion rate will produce a much smaller effect than a decrease in the enrolment rate of the same magnitude.

It is worth noting that these simulations do not control for any other changes in conditional promotion or enrolment rates that occurred between 1997 and 2003. Of course, factors other than the two policies that we focus on could potentially also have had some influence on promotion rates. These include higher expectations among parents and learners after the political transition; the effect of the outcomes-based educational philosophy on teacher perceptions on repetition; a new crop of teachers that were trained in this philosophy; and increased competition for learners in the post-apartheid dispensation, which may have made some poor schools more reluctant to have learners repeat (out of fear that they would leave and go to other schools). Similarly, changes in preferences or expectations regarding labour market outcomes could have contributed to falling enrolment rates. However, it is difficult to think of reasons why these changes would have had a strong influence on educational throughput or enrolment, and even more unlikely that they could have given rise to the timing of the changes we have observed. The fact that the magnitude and timing of these changes over different ages and schooling years corresponded very closely to what one would expect from the schooling policies, makes the above interpretation highly plausible.

\section{The unintended consequences on labour market outcomes}

\subsection{Changes in reason for economic inactivity}

When considering the effect of these age restrictions on labour force participation and unemployment rates, it is informative to express over-aged learners as a share of the total population. In 1999 8.3\% of the working age population was in school and over-aged, whereas the share had dropped to $5.2 \%$ of the population by 2003 . In a labour market that already failed to provide employment opportunities for a very high share of job seekers, this meant that $3.1 \%$ of the working age switched from "studying" to either being "unemployed" or still "economically inactive" (but now reporting a different reason for their inactivity). This constitutes approximately one-half of the total increase in the participation rate over 
this period, and means that a substantial part of the concurrent rise in unemployment may have been driven by the implementation of these school age-restrictions.

Figure 6 compares the share of the non-employed working age population that were classified as being either unemployed or economically inactive due to studying (either as an over-aged or "normal-aged" student), engaging in household production, retirement or one of a range of other activities in 1999 and 2003. The share that was unemployed grew by 10 percentage points over this period, about half of whom were drawn from over-aged students (who experienced a 5 percentage point decline). Other contributors were housewives, retirees and normal-aged students, each of which contributed one percentage point.

[Insert figure 6 here]

\subsection{Birth cohort decomposition}

The above analyses used a comparative-static approach to investigate the effects of the schooling policy by contrasting the labour market outcomes and schooling decisions of individuals in different survey years. However, schooling investment and labour market participation choices are inherently dynamic decisions that depend on life-cycle and business cycle considerations and are affected by unobserved effects such as expectations and cultural norms. In order to control more comprehensively for these issues, we now proceed to a birth cohort analysis of the participation decision. More specifically, we decompose the participation rate into parts that are attributable to time-, age- and birth year-specific components for the different race and gender groups. This allows us to focus on how the participation decisions of members of different generations differed, after controlling for the typical life-cycle participation pattern and variation in the business cycle. Furthermore, this method allows us to examine the extent to which these changes were affected by observable characteristics that correspond to some of the hypotheses discussed above. For a more comprehensive and technical explanation of the decomposition method used here, see Burger and Von Fintel (2009).

Figure 7 plots the participation-cohort effects for each gender for blacks and whites, which show that the generational experiences of the various race and gender groups differed markedly. Amongst the oldest birth cohorts, male participation was much higher than female participation (for both blacks and whites) and black participation was slightly lower than that of whites (for both genders). Two trends are discernible from the cohort effects. Firstly, for those cohorts born before 1975 (aged 20 or above in 1995), female participation rates converged on those of males for both the population groups shown: there was only a 
gradual increase in participation across more recent male birth cohorts, whereas the younger female cohorts experienced a more rapid increase in participation. This reflects the "feminisation" of the labour market over generations (Casale \& Posel, 2002). However, "feminisation" is referred to in the relative sense, as this hypothesis cannot explain why male participation also increased across generations, albeit at a slower pace.

Secondly, whereas these increases in participation rates appeared to have levelled off for white men and women born after 1975, the participation rates for black men and women born between 1975 and 1982 accelerated, with some stabilisation for those born after 1982 . These groups represent labour market entrants in the period 1997 to 2002, who were the first cohorts to be affected by the implementation of the over-age schooling restrictions.

[Insert figure 7 here]

Our interest in this paper is primarily with the second of these trends. In order to identify the reason for this sudden increase in participation, we now restrict our attention to black men and women only, and add control variables to our decomposition analysis. In particular, we test the hypothesis that participation decisions of recent labour market entrants were based on their higher educational attainment, lower marital rates (for females) and other changes in household structure, as suggested by Casale \& Posel (2002). Females entering the labour market more recently were more likely to head households, were more educated and less likely to be married, prompting increases in labour market attachment for these groups. Further, in recent years the number of unemployed supported by each household increased, so that labour force participation among potential breadwinners probably increased (Klasen \& Woolard, 2008).

[Insert figure 8 here]

Figure 8 compares the cohort profiles before and after controlling for the aforementioned factors. For black males, the generational profile becomes virtually flat after adding the controls, implying that those born between 1930 and 1975 would have had a remarkably similar propensity to participate had they received the same education and made the same household decisions. Assuming that, according to traditional roles, household formation did not have as large a participation impact on males as on females, differences in education across generations explained the rise in participation rates for recent male labour market entrants. However, it is evident that the "discontinuity" on the horizontal profile that arose for those born between 1975 and 1982 cannot be explained by educational attainment alone. This surge in participation that stabilised at higher levels for these groups was apparently due to another exogenous shock. The other factors that we control for also do not fully account for the differences across genders. Furthermore, their role in explaining the generational rise in female participation rates is also not as clear as for males. However, the strong climb is dampened slightly by the education and household controls, and confirms their role in 
driving the feminisation of the labour market (Casale \& Posel, 2002). Nevertheless, these variables also cannot account for the sudden and sustained increase in female participation for the most recent labour market entrants.

To explore this phenomenon further, note that the economically inactive population consisted, to a large degree, of individuals still in school. Transition into the labour market was more likely to occur within this group than for other non-participants. As discussed in section 4, the proportion of individuals between the ages of 18 and 30 who were still in education declined substantially between 1997 and 2003. This age group in that time corresponded with the recent birth cohorts for which the participation rate surged. It is therefore likely that instead of making the transition out of education into other forms of inactivity, for instance into further education and training, or into employment, these groups have been pushed into unemployment.

[Insert figure 9 here]

Figure 9 is derived from adding a control (in addition to the variables accounted for in Figure 8) for the proportion of non-participants currently in school. It is evident that we now do indeed observe cohort profiles that are consistent across all birth years. The participation discontinuity is therefore likely to be driven by faster transitions from the schooling system into the labour market for younger generations. This suggests that overaged learners rejected the option of pursuing further education and training in favour of entering the labour market, probably because of the restrictions placed on their remaining in school. This has compounded the longer-term effect of rising participation rates, so that this trajectory intensified, resulting in a sustained higher level of participation for the most recent labour market entrants. In light of the fact that employment rates for this group have not increased proportionally, enrolment policies have had the unintended side effect of swiftly adding a large group of individuals to an already steadily lengthening job queue. For this reason, the current generation of youths does not only face higher unemployment as a result of its age or inexperience, but because of rapid exit from the education system. This has contributed markedly to the rise in unemployment in post-apartheid South Africa.

\section{Conclusion}

This paper has discussed the implementation of over-aged schooling restrictions and higher promotion rates and demonstrated that these policies have had a large impact on schooling and labour market decisions of young South Africans. The country's high level of unemployment clearly poses a serious deterrent to improving the livelihoods of South Africa's poor. The paper has shown that the increase in the unemployment rate was not so much the result of a deteriorating ability of the economy to create jobs, but was rather largely driven by increased participation rates in the labour market. The reforms of school-age 
policies were a response by the education authorities to the large numbers of over-age learners in the system who were perceived as making limited educational progress and crowding existing resources. The country has long suffered from high unemployment, and the late 1990s and early 2000s brought this problem to the fore to a greater extent as a large group of the unemployed were no longer allowed to hide in the school system.

This unintended effect of the restriction on over-age learners and more lenient promotion policies have brought into the open a problem that was long festering. It thereby raises important policy issues. One of these relates to educational alternatives for those unsuccessful at school, but who are ill-equipped with skills to successfully enter a modern labour market. The debate around FET colleges relates to this issue. A second important issue that has attracted growing attention since these age restrictions were introduced is that of youth unemployment and labour market policies to deal with this matter. These issues will remain an important part of South African educational and labour market debates for some time to come.

\section{Bibliography}

Banerjee, A. et al., 2008. Why has unemployment risen in the New South Africa?. Economics of Transition, October , 16(4), p. 715-740.

Banerjee, A. et al., 2007. Why Has Unemployment Risen in the New South Africa, Cambridge, MA: NBER Working Paper No. 13167.

Bhorat, H., 2004. Labour Market Challenges in the Post-Apartheid South Africa. South African Journal of Economics, 72 (5), pp. 954-977.

Bhorat, H. \& Hodge, J., 1999. Decomposing Shifts in Labour Demand in South Africa. South African Journal of Economics, September , 67(3), pp. 155-168.

Branson, N. \& Wittenberg, M., 2007. The Measurement Of Employment Status In South Africa Using Cohort Analysis, 1994-2004. South African Journal of Economics, 75(2), pp. 313326.

Burger, R. P. \& Von Fintel, D., 2009. Determining the Causes of the Rising South African Unemployment Rate: An Age, Period and Generational Analysis. Working Papers 158, Economic Research Southern Africa.": s.n.

Burger, R. P. \& Woolard, I., 2005. The state of the labour market in South Africa after the first decade of democracy. Journal of vocational education and training, 57(4), pp. 453-476. Casale, D. \& Posel, D., 2002. The continued feminisation of the labour force in South Africa: An analysis of recent data and trends. South African Journal of Economics, March , 70(1), p. 156-184.

Deaton, A., 1997. The Analysis of Household Surveys - A Microeconometric Approach to Development Policy. Baltimore: Johns Hopkins University Press.

Department of Education, 1998. Age requirements for admission to an ordinary public government school. Government Gazette no. 2433 of 1998.

Guluza, X. \& Hoadley, U. K., 1998. Learner Progress and Achievement Study: Research report 2, Braamfontein: Joint Education Trust.

Hofmeyr, C., 2011. How does the process of educational attainment differ between Africans and Coloureds in the Western Cape?", s.l.: University of Cape Town. 
Klasen, S. \& Woolard, I., 2008. Surviving Unemployment Without State Support:

Unemployment and Household Formation in South Africa. Journal of African Economies, 18(1), pp. 1-51.

Kraak, A., 2008. The education-economy relationship in South Africa, 2001-2005. In: A.

Kraak \& K. Press, eds. Human Resources Development Review 2008. Cape Town: HSRC Press, pp. 1-25.

Lam, D., Ardington, C. \& Leibbrandt, M., 2011. Schooling as a lottery: Racial differences in school advancement in urban South Africa. Journal of Development Economics, July, 95(2), pp. 121-136.

Mlatsheni, C. \& Rospabé, S., 2002. Why is Youth Unemployment so High and Unequally spread in South Africa?, s.l.: Development Policy Research Unit, University of Cape Town..

Ntuli, M., 2007. Determinants of South African Women's Labour Force Participation, 1995-2004, s.1.: Institute for the Study of Labor, University of Bonn.

Perry, H. \& Arends, F., 2003. Public Schooling. In: Human Resources Development Review 2003.

Cape Town: HSRC Press, pp. 303-325.

Republic of South Africa, 1995. Meeting the Commitment to Free and Compulsory General Education. Chapter 13.White Paper on Education and Training. Notice 196 of 1995. Department of Education. Available [Online]: [Online]

Available at: http://www.polity.org.za/html/govdocs/white papers/educ5.html

Seekings, J. \& Nattrass, N., 2005. Class, Race, and Inequality in South Africa. New Haven: Yale University Press.

Western Cape Education Department, 2003. Admission Of Over-Age Learners To Public Schools. [Online]

Available at: http://wced.wcape.gov.za/circulars/2003/e240 03.html

$\mathrm{Yu}, \mathrm{D} ., 2007$. The comparability of the Statistics South Africa October Housebold Surveys and Labour Force Surveys, Stellenbosch Working Papers No. 2007/13, Stellenbosch: University of Stellenbosch. 
Table 1: Labour force status, by survey year: 1995-2007

\begin{tabular}{ccccccc}
\hline Survey & Employed & Unemployed & $\begin{array}{c}\text { Economically } \\
\text { inactive }\end{array}$ & $\begin{array}{c}\text { Employment } \\
\text { rate }\end{array}$ & $\begin{array}{c}\text { Unemployment } \\
\text { rate }\end{array}$ & $\begin{array}{c}\text { Participation } \\
\text { rate }\end{array}$ \\
\hline OHS1995 & $9,499,347$ & $4,231,726$ & $10,459,510$ & $39.3 \%$ & $30.8 \%$ & $56.8 \%$ \\
OHS1996 & $8,966,307$ & $4,566,316$ & $11,376,442$ & $36.0 \%$ & $33.7 \%$ & $54.3 \%$ \\
OHS1997 & $9,093,647$ & $5,201,950$ & $11,209,560$ & $35.7 \%$ & $36.4 \%$ & $56.0 \%$ \\
OHS1998 & $9,370,130$ & $5,626,470$ & $10,668,633$ & $36.5 \%$ & $37.5 \%$ & $58.4 \%$ \\
OHS1999 & $10,356,143$ & $5,875,126$ & $10,015,276$ & $39.5 \%$ & $36.2 \%$ & $61.8 \%$ \\
LFS2000b & $12,224,406$ & $6,371,833$ & $9,177,929$ & $44.0 \%$ & $34.3 \%$ & $67.0 \%$ \\
LFS2001b & $11,167,541$ & $7,640,439$ & $9,276,017$ & $39.8 \%$ & $40.6 \%$ & $67.0 \%$ \\
LFS2002b & $11,283,924$ & $8,120,761$ & $9,090,403$ & $39.6 \%$ & $41.8 \%$ & $68.1 \%$ \\
LFS2003b & $11,411,351$ & $8,198,365$ & $9,296,514$ & $39.5 \%$ & $41.8 \%$ & $67.8 \%$ \\
LFS2004b & $11,630,196$ & $8,074,148$ & $9,566,059$ & $39.7 \%$ & $41.0 \%$ & $67.3 \%$ \\
LFS2005b & $12,287,798$ & $7,790,699$ & $9,584,882$ & $41.4 \%$ & $38.8 \%$ & $67.7 \%$ \\
LFS2006b & $12,787,285$ & $7,599,053$ & $9,586,233$ & $42.7 \%$ & $37.3 \%$ & $68.0 \%$ \\
LFS2007b & $13,293,327$ & $7,339,549$ & $9,754,526$ & $43.7 \%$ & $35.6 \%$ & $67.9 \%$ \\
\hline \hline
\end{tabular}

Source: Own calculations from OHS and LFS data (Statistics South Africa, various years)

Table 2: School enrolment totals, by year: 1998-2003

\begin{tabular}{|c|c|c|c|c|}
\hline & $\begin{array}{l}\text { Total school } \\
\text { enrolment: } \\
\text { Grade 1-12 }\end{array}$ & $\begin{array}{l}\text { Total school } \\
\text { enrolment: } \\
\text { Grade 1-12 } \\
\end{array}$ & $\begin{array}{l}\text { Total school } \\
\text { enrolment: } \\
\text { Grade } 1-12 \text {, } \\
\text { age }>14\end{array}$ & $\begin{array}{c}\text { Over-aged } \\
\text { learners in } \\
\text { school } \\
\end{array}$ \\
\hline Source & DoE & \multicolumn{3}{|c|}{ OHSs \& LFSs } \\
\hline 1998 & $12,082,009$ & & & \\
\hline 1999 & $12,040,021$ & $13,945,675$ & $4,068,687$ & $2,683,336$ \\
\hline 2000 & $11,600,365$ & $13,106,789$ & $3,967,938$ & $2,393,986$ \\
\hline 2001 & $11,657,358$ & $12,805,102$ & $3,663,102$ & $2,151,511$ \\
\hline 2002 & $11,574,437$ & $13,289,911$ & $3,808,007$ & $2,039,925$ \\
\hline 2003 & $11,657,358$ & $13,431,356$ & $3,666,661$ & $1,817,874$ \\
\hline Decrease: 1998-2003 & $-424,651$ & & & \\
\hline Decrease: 1999-2003 & $-382,663$ & $-514,319$ & $-402,026$ & $-865,462$ \\
\hline
\end{tabular}


Figure 1: Participation and unemployment rates: 1995-2007

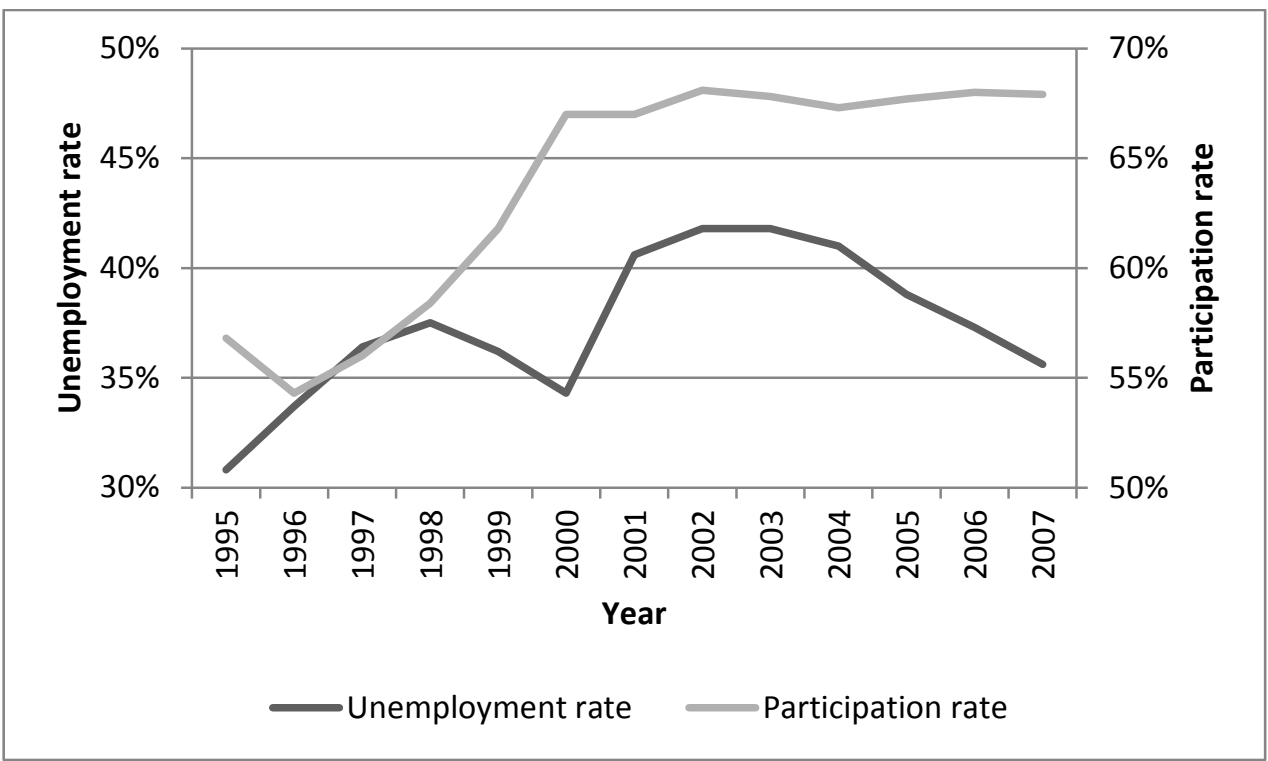

Source: Own calculations from OHS and LFS data (Statistics South Africa, various years)

Figure 2: Number of matric candidates, by year: 1979-2005

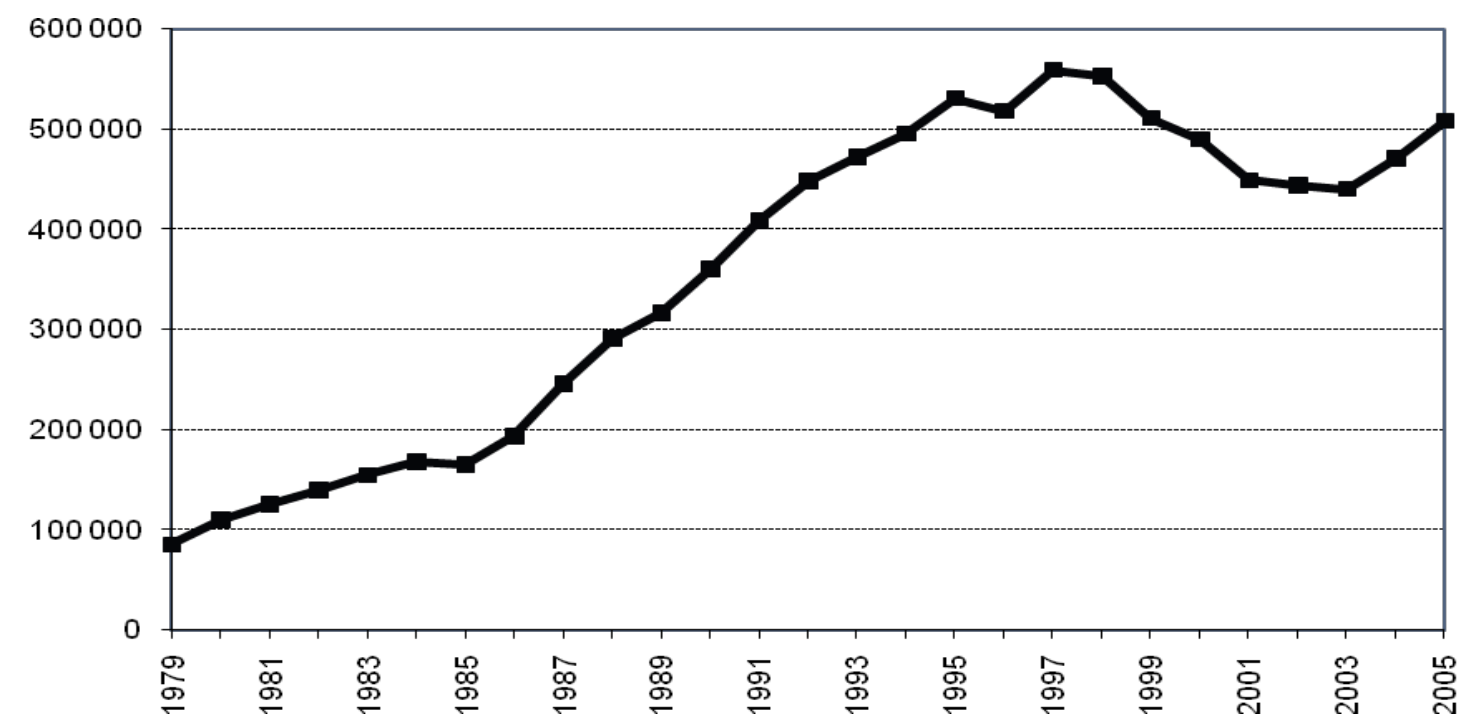

Source: Own calculations from information obtained from Department of Basic Education 
Figure 3: Share of age group that is at school and over-aged, 1997 and 2003

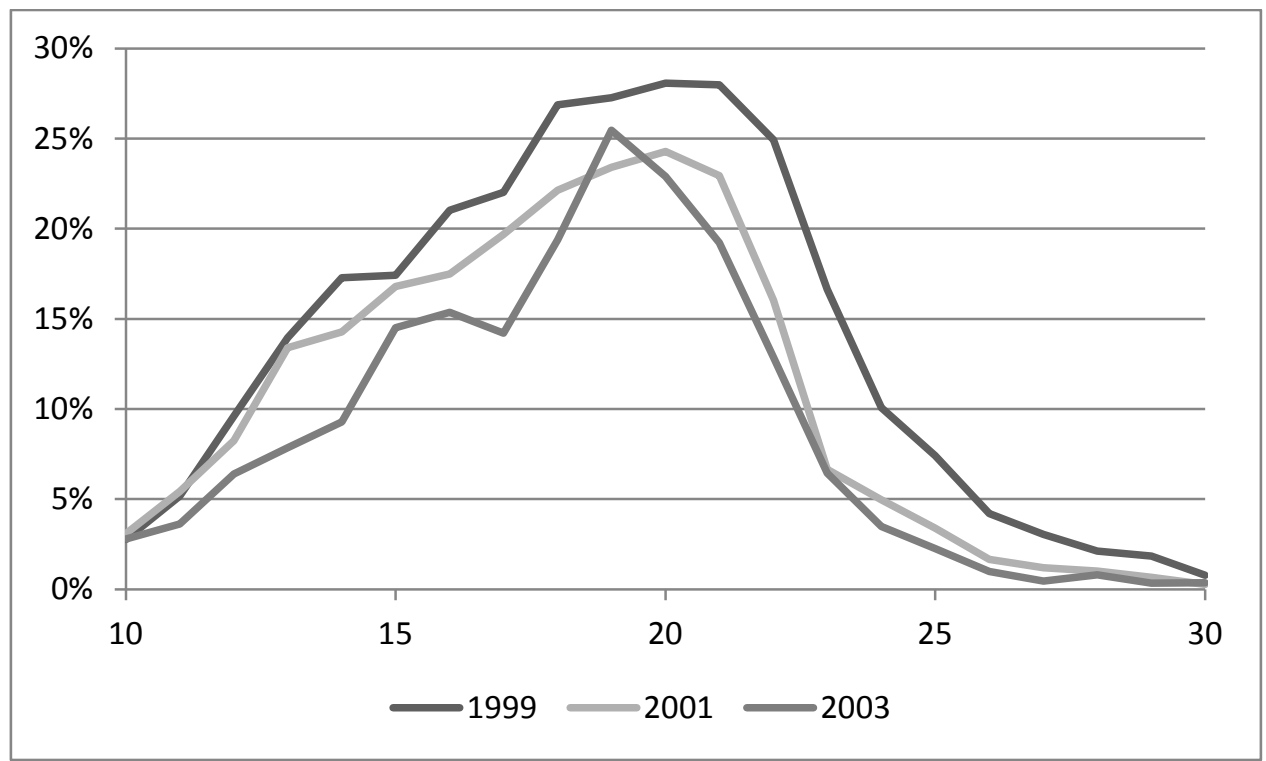

Source: Own calculations from OHS and LFS data (Statistics South Africa, various years) 
Figure 4: Promotion and enrolment rate estimates, by age, schooling phase and period
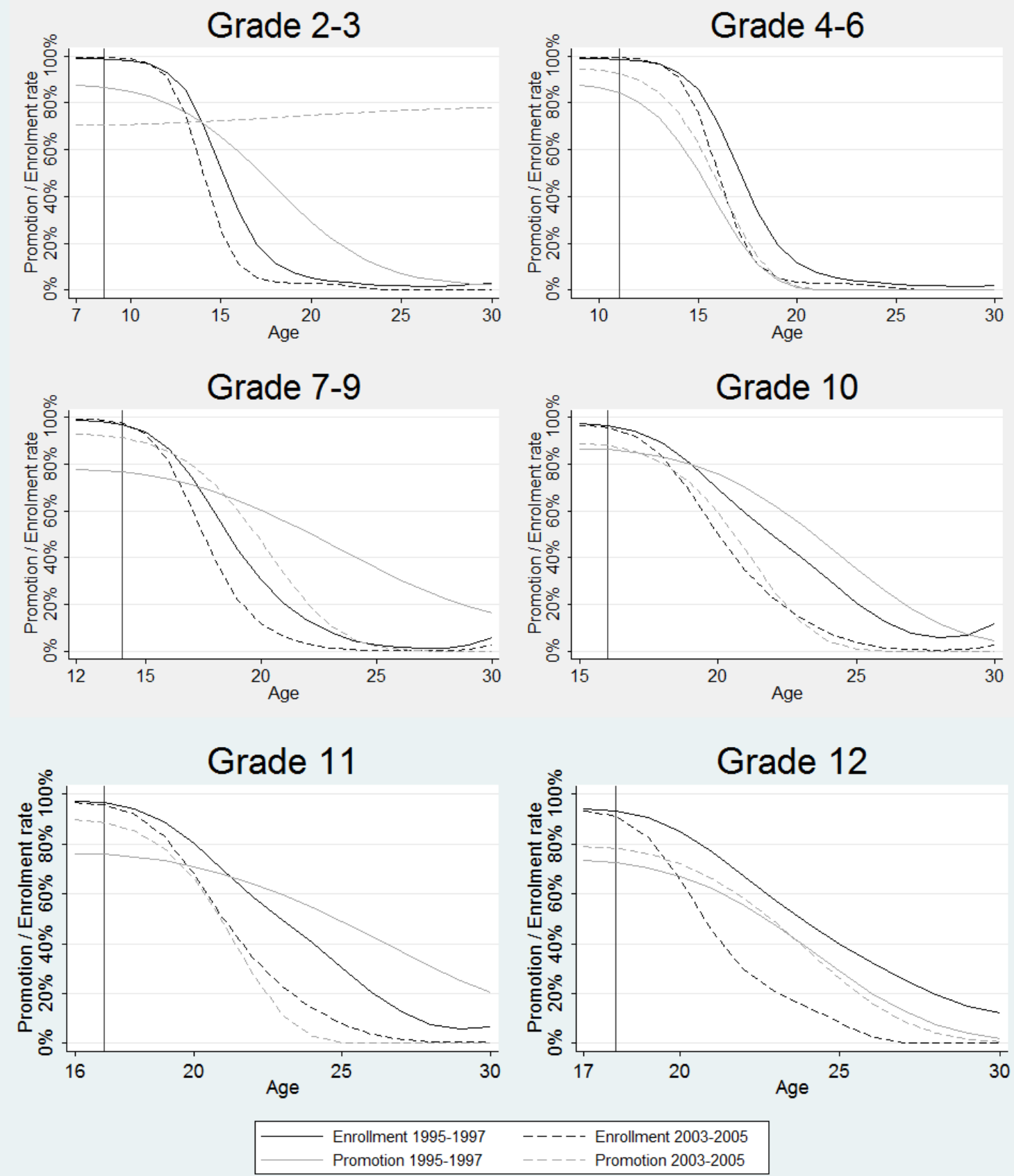

Source: Own calculations from OHS and LFS data (Statistics South Africa, various years) 
Figure 5: Share of 15-30 year-olds enrolled in school, 1995-2007

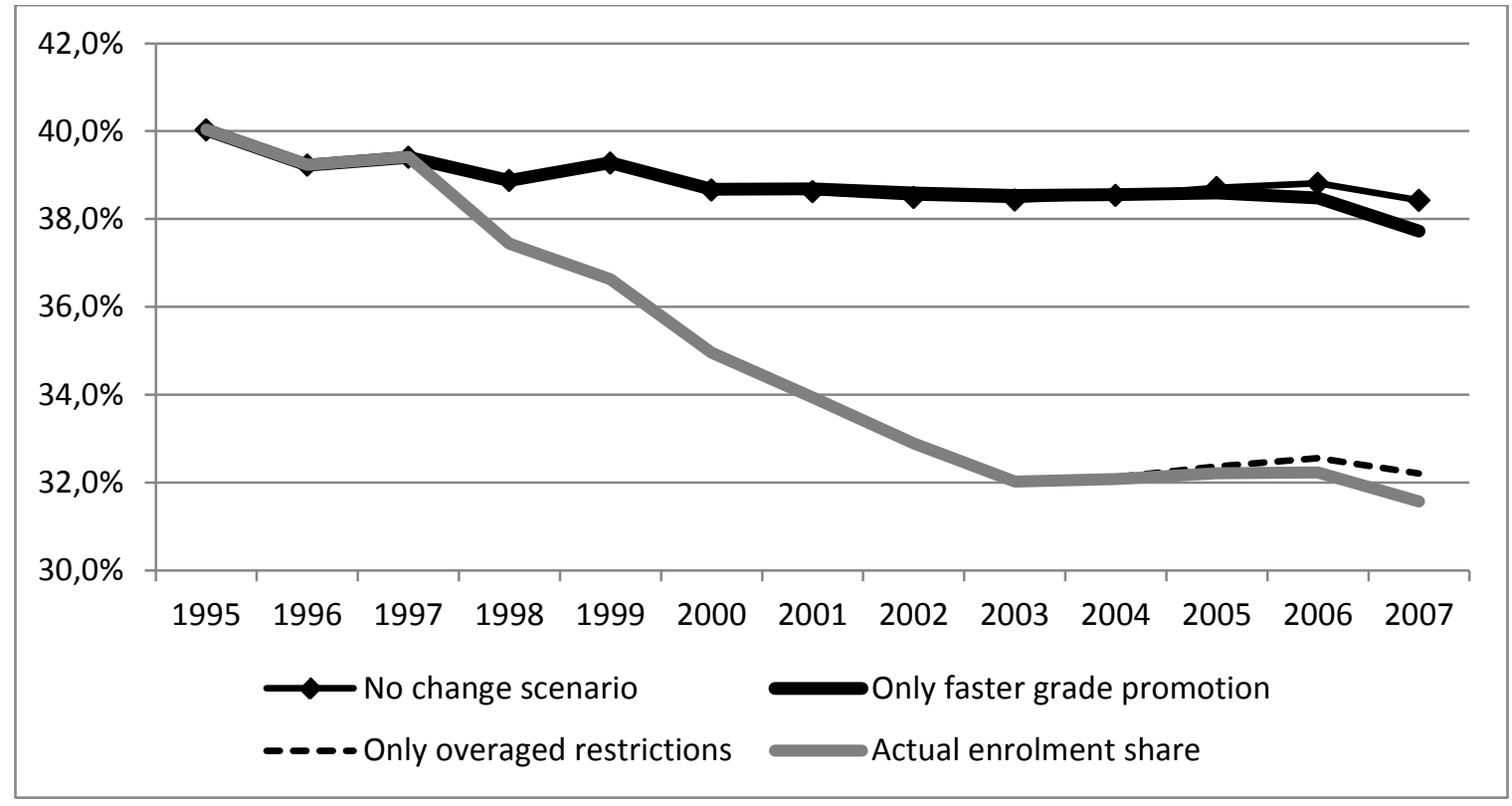

Source: Own calculations from OHS and LFS data (Statistics South Africa, various years)

Figure 6: Shares of non-employed engaged in various activities: 1999 and 2003

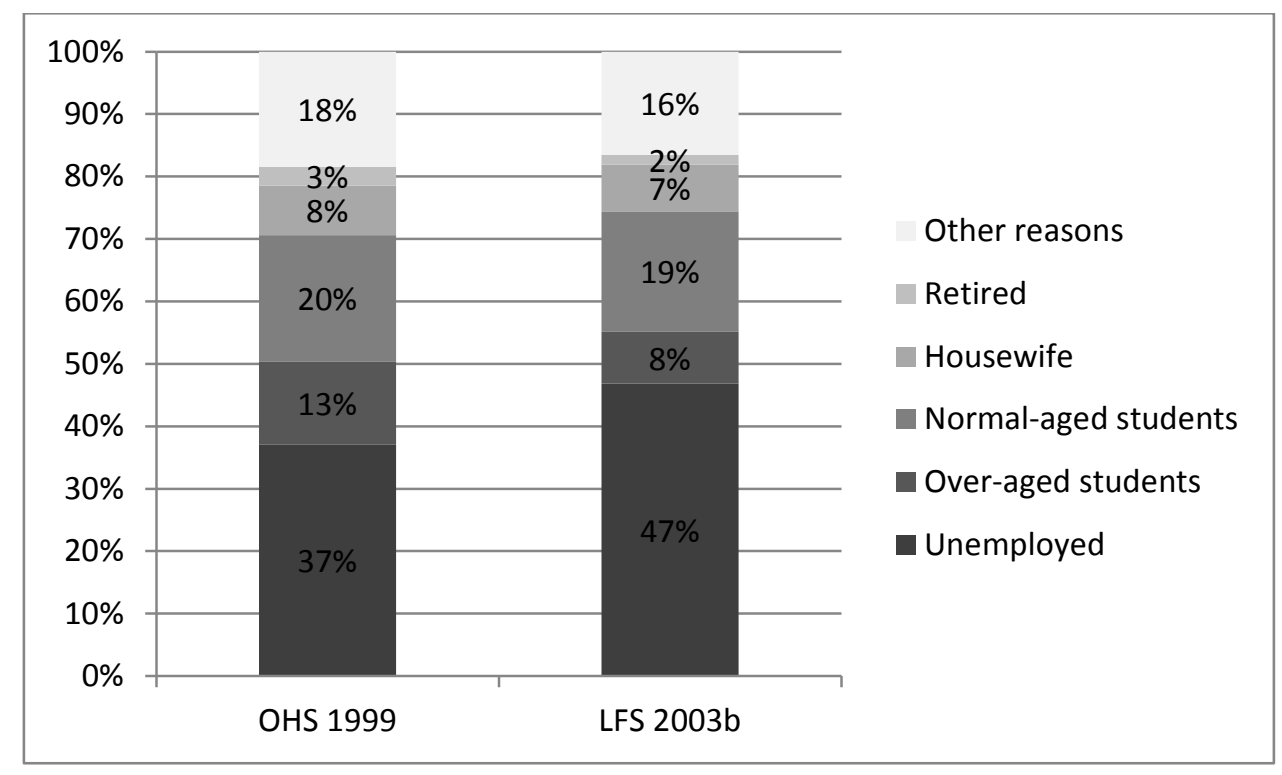

Source: Own calculations from OHS and LFS data (Statistics South Africa, various years) 
Figure 7: Generational component of participation decision, by birth year, race and gender, controlling for life cycle and business cycle effects

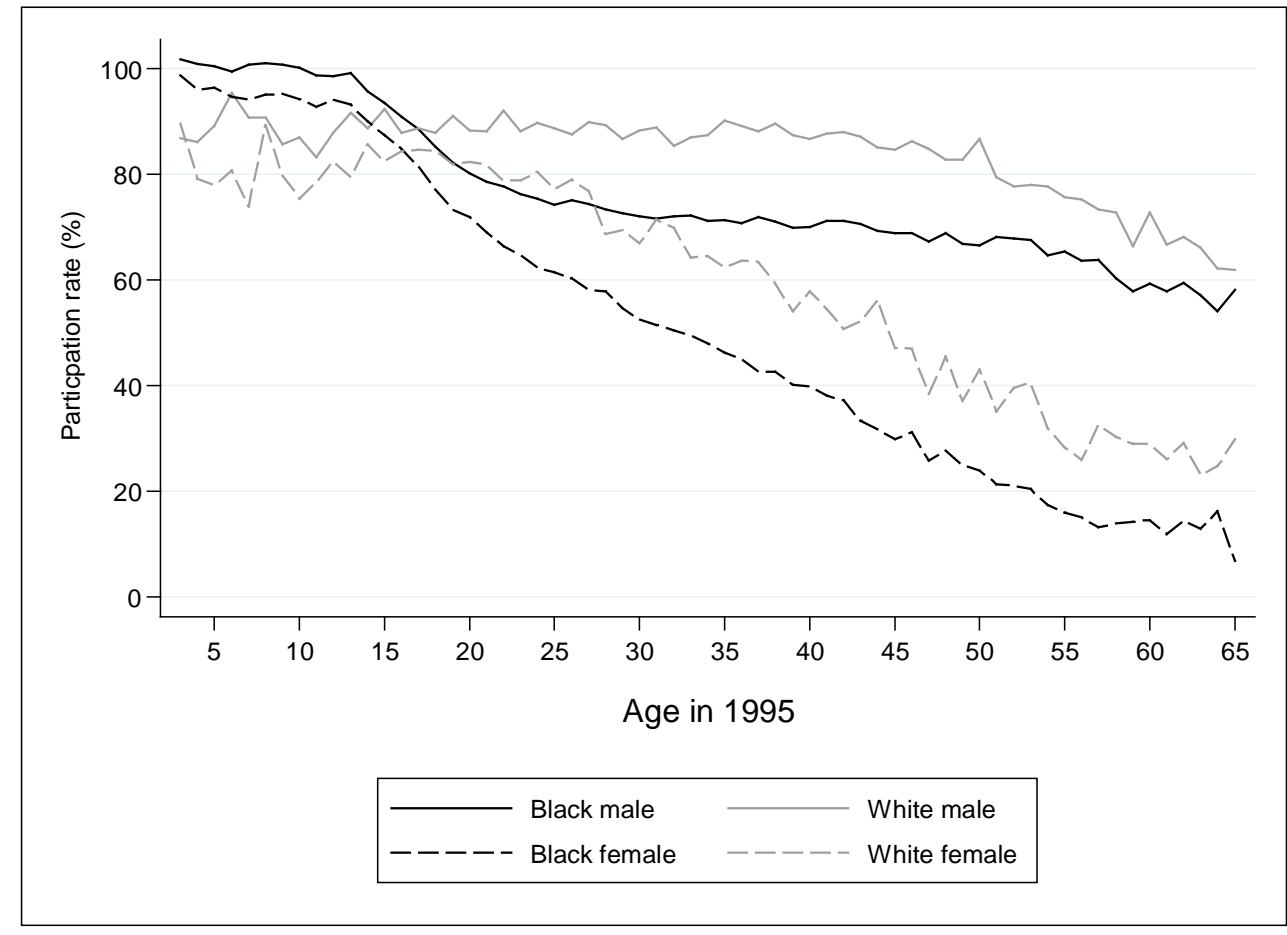

Source: Own calculations from OHS and LFS data (Statistics South Africa, various years)

Figure 8: Generational component of participation decision, after controlling for life cycle and business cycle effects, educational attainment, marital status and household structure

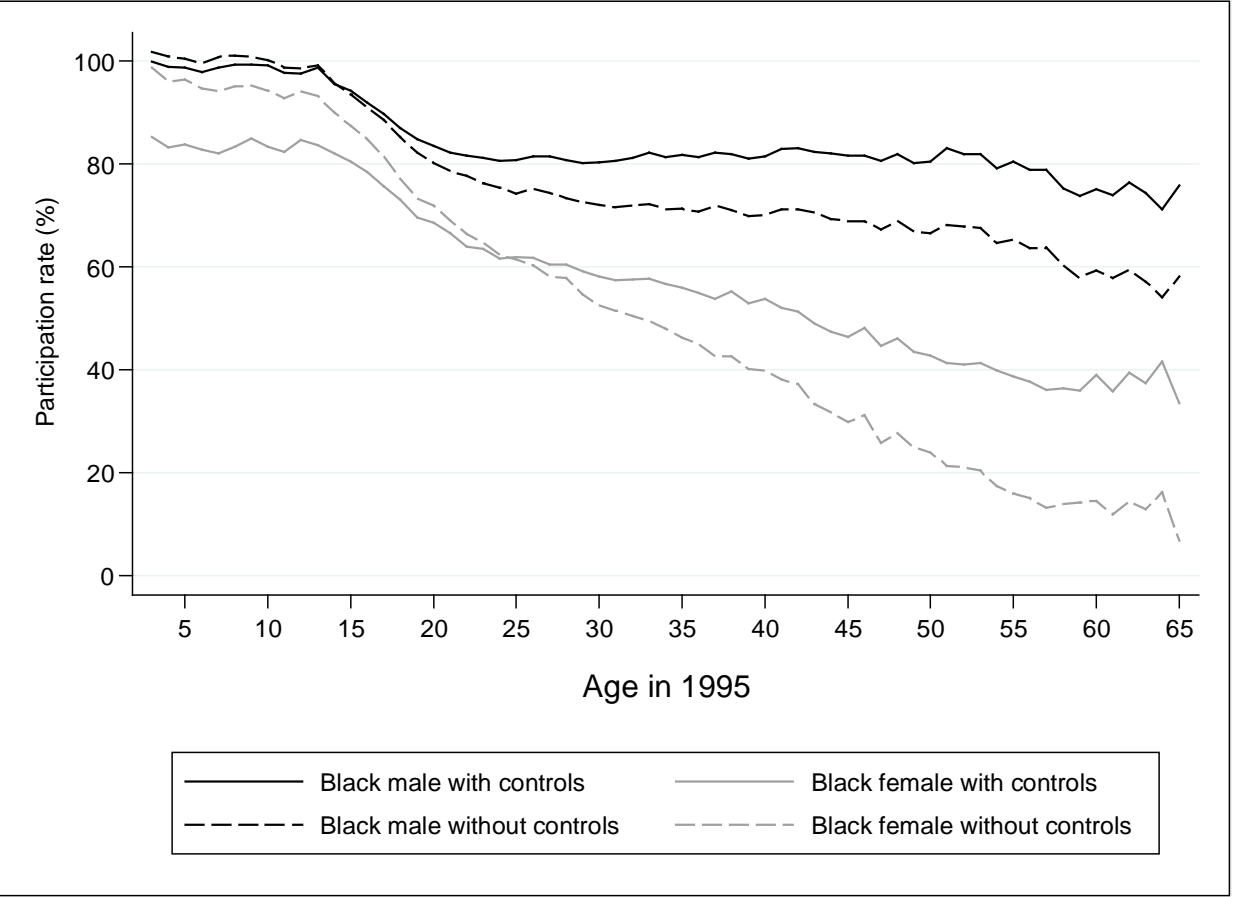

Source: Own calculations from OHS and LFS data (Statistics South Africa, various years) 
Figure 9: Generational component of participation decision, after controlling for life cycle and business cycle effects, participants still at school

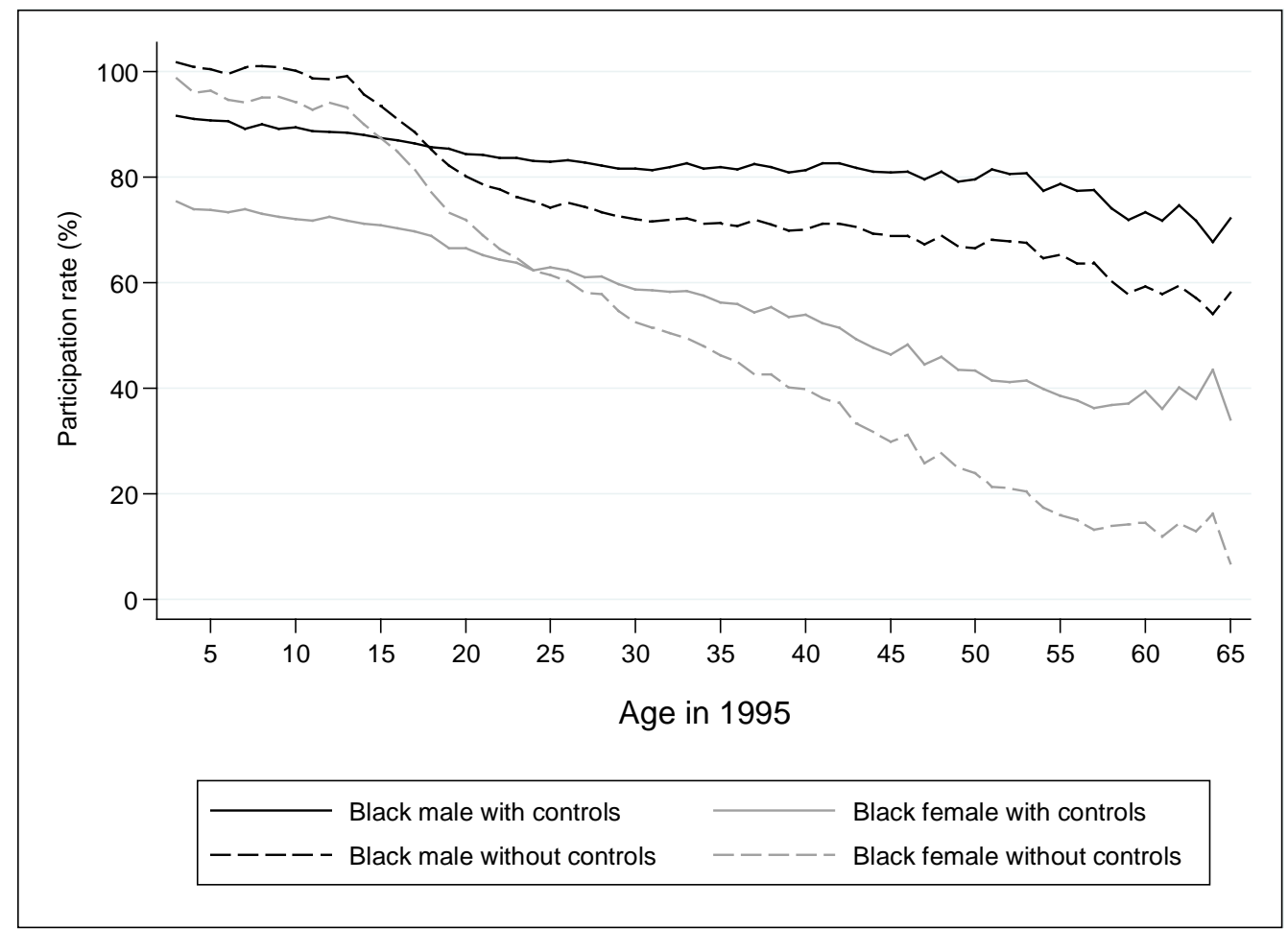

Source: Own calculations from OHS and LFS data (Statistics South Africa, various years) 